\title{
Assessing the association of single nucleotide polymorphisms in thyroglobulin gene with age of puberty in bulls
}

\author{
María Elena Fernández ${ }^{1,3+}$, Daniel Estanislao Goszczynski ${ }^{1,3 \dagger}$, Alberto José Prando², Pilar Peral-García1, \\ Andrés Baldo², Guillermo Giovambattista ${ }^{1 *}$ and Juan Pedro Liron ${ }^{1 *}$
}

\begin{abstract}
Puberty is a stage of sexual development determined by the interaction of many loci and environmental factors. Identification of genes contributing to genetic variation in this character can assist with selection for early pubertal bulls, improving genetic progress in livestock breeding. Thyroid hormones play an important role in sexual development and spermatogenic function. The objective of this study was to evaluate the association between single nucleotide polymorphisms (SNPs) located in thyroglobulin(TG) gene with age of puberty in Angus bulls. Four SNPs were genotyped in 273 animals using SEQUENOM technology and the association between markers and puberty age was analyzed. Results showed a significant association $(P<0.05)$ between these markers and puberty age estimated at a sperm concentration of 50 million and a progressive motility of $10 \%$. This is the first report of an association of TG polymorphisms with age of puberty in bulls, and results suggest the importance of thyroidal regulation in bovine sexual development and arrival to puberty.
\end{abstract}

Keywords: Bovine, Puberty, Polymorphism, Thyroglobulin, Association study

\section{Background}

Puberty is a stage of sexual development determined by the interaction of many loci hierarchically arranged in networks, and environmental factors (Ojeda et al., [1]). Puberty in cattle is an important target for genetic improvement so early prediction using genetic markers is a goal for livestock breeding. The identification of new genes and/or mutations contributing to genetic variation in puberty can assist with the selection for early pubertal bulls, reducing the generation interval and increasing fertility and genetic progress (Johnston et al., [2], Fortes et al., [3]).

Thyroid hormones (THs) exert a broad range of effects on metabolism, growth, homeostasis control, and other biological processes (Warner and Mittag, [4], Mullur et al., [5]), and show connection with nearly every biological endocrine system. Several studies provide evidence to confirm the role

\footnotetext{
* Correspondence: ggiovam@fcv.unlp.edu.ar; juanpedroliron@gmail.com ${ }^{\dagger}$ Equal contributors

'Instituto de Genética Veterinaria (IGEVET), CCT La Plata - CONICET - Facultad de Ciencias Veterinarias, Universidad Nacional de La Plata, Calle 60 y 118 s/n, La Plata B1900AVW, CC 296, Argentina

Full list of author information is available at the end of the article
}

of THs in sexual differentiation and gonadal development (Jannini et al., [6], Mendis-Handagama and Siril Ariyaratne, [7], Flood et al., [8], Duarte-Guterman et al., [9]). For example, it has been discovered that deiodinases [the enzymes responsible for ioding thyroglobulin (TG) to obtain the active forms triiodothyronine (T3) and thyroxine (T4)] and thyroid receptors (TRs, encoded by $\operatorname{tr} \alpha$ and $\operatorname{tr} \beta$ genes) are present within gonadal tissues, suggesting that THs must have an action on these organs (Wagner et al., [10]). The presence of $\mathrm{TH}$ machinery in testicular tissues implies that $\mathrm{TH}$ axis must regulate aspects of testicular functioning. Indeed, it has been shown that hypo- and hyperthyroid males exhibit testes and sperm dysfunction (Krassas et. al., [11]). In addition, THs are involved in the regulation of androgen receptors(ARs) expression in testicular tissues through thyroid response elements (TREs) located in the promoter of ar genes(Flood et al., [8]). Furthermore, THs may also regulate other genes involved in androgen biosynthesis and signaling. For example, THs enhance $5 \alpha$-reductase expression and activity within the testes, increasing $5 \alpha$-dihydrotestosterone concentrations (Ram and Waxman, [12], Duarte-Guterman et al., [9]). On the other hand, it has 
been reported that $\mathrm{TH}$-related transcription factors influence the expression of $\operatorname{sox} 9$, which induces differentiation of the bipotential cells in the testes into Sertoli cells (Zhou et al., [13]). Sox9 stimulates the nuclear receptor steroidogenic factor 1 ( $s f 1$ ), which is primarily expressed in Leydig cells and plays an important role in sexual differentiation (Zhao et al., [14]). Dax1 gene works in parallel with $s f 1$ to regulate testicular differentiation and can regulate $\mathrm{TH}$-related gene expression (Sugawara et. al., [15]).

Beyond the fact that THs have considerable effects on the hypothalamic-pituitary-gonadal axis (HPG) and sexual development, some studies examined the involvement of androgens in $\mathrm{TH}$ synthesis and metabolism. For example, gonadotropin-releasing hormone $(\mathrm{GnRH})$ interferes with the hypothalamic-pituitary-thyroid axis (HPT), increasing thyroid stimulating hormone (TSH) secretion. Moreover, ARs were identified in the thyroid gland of different vertebrate species, suggesting that the androgen axis directly regulates $\mathrm{TH}$ synthesis and metabolism (Pelletier et al., [16]). Other works have demonstrated the potential of ARs to regulate $\mathrm{TH}$ axis showing that TRs transcriptional levels and distribution within testes are responsive to androgen fluctuations through the presence of androgen response elements (AREs) in the promoter regions of $\mathrm{TH}$-related genes. These evidences demonstrate the existence of a considerable cross-regulation between both axes.

Considering the existing evidence on the biological connection between metabolic status, regulated to a large extent by thyroid hormones, and sexual development, and taking into account the fact that THs play a role in the regulation of sexual function, we decided to evaluate the possible associations between SNPs located in the 3 ' flanking region of TG gene with the age of puberty in bull calves.

\section{Methods}

In order to reach this objective, DNA was extracted from blood samples belonging to 273 Angus bulls using Wizard Genomic kit, following manufacturer instructions (Promega, Madison, WI, USA). Four SNPs (rs378215592, rs110406764, rs109662686, rs109057985) in TG previously reported by Hou et al., [17] were genotyped using SEQUENOM platform by GeneSeek Inc. genotyping services (Lincoln, NE, USA). This technology is based on primer-extension reaction that generates allele-specific products with distinct masses, which are then detected through MALDI-TOF mass spectrometry (www.sequenom.com/). Detailed information of the studied SNPs is presented in Table 1. Animal samples, phenotypic measurements and estimation of puberty ages used in this work were reported in Liron et al., [18]. The estimated puberty ages were: i. age at $28 \mathrm{~cm}$ of scrotal circumference (SC28),
Table 1 Information of single nucleotide polymorphisms (SNP) used in this work

\begin{tabular}{ccccc}
\hline SNP & Gene-Chromosome & $\begin{array}{c}\text { Gene } \\
\text { region }\end{array}$ & $\begin{array}{c}\text { Position } \\
\text { (UMD 3.1) }\end{array}$ & $\begin{array}{c}\text { Allele } \\
\text { change }\end{array}$ \\
\hline rs378215592 & TG- Ch14 & 3' UTR & 9281431 & T/C \\
rs110406764 & TG- Ch14 & 3' UTR & 9281469 & $\mathrm{G} / \mathrm{A}$ \\
rs109662686 & TG- Ch14 & 3' UTR & 9281507 & $\mathrm{~A} / \mathrm{G}$ \\
rs109057985 & TG- Ch14 & 3' UTR & 9281510 & T/G \\
\hline
\end{tabular}

and ii. age at sperm concentration 50 million and percentage of progressive motility 10\% (C50 - M10). In order to evaluate the linkage disequilibrium (LD) between the three studied SNPs, the haplotypes for each individual were constructed using Phase algorithm (Li and Stephens, [19]).

The association between haplotype markers of TG gene and the estimated puberty ages was analyzed utilizing MIXED procedure implemented in SAS 9.0 software (SAS Inst. Inc.). The linear mixed model used to analyze the association between puberty age and genotypes was the following:

$$
Y_{i j k l}=\mu+S_{i}+G_{j}+B_{k}+O_{l}+e_{i j k I}
$$

Where $Y_{\mathrm{ijkl}}=$ phenotypic observation of the I bull, $\mu=$ the overall mean, $S_{i}=$ the fixed effect of $i^{\text {th }}$ year, $G_{j}=$ the fixed effect of $j^{\text {th }}$ genotype, $B_{k}=$ the fixed effect of $k^{\text {th }}$ herd, $\mathrm{O}_{\mathrm{l}}=$ random effect of $\mathrm{l}^{\text {th }}$ sire, and $\mathrm{e}_{\mathrm{ijkI}}=$ random error.

\section{Results and discussion}

After analyzing the genotyping results, one SNP (rs109662686) was removed given that it exhibited a call rate lower than $57 \%$. The LD analysis indicated that the three remaining SNPs were completely linked $\left(r^{2}=1\right)$. Only two (TGT and CAG) of the eight possible haplotypes were found, with gene frequencies of 0.81 and 0.19 for TGT and CAG haplotypes, respectively. Genotype frequencies values were 0.64 for homozygote TGT, 0.03 for homozygote CAG and 0.33 for heterozygote bulls. The obtained haplotypes for the 273 bulls were tested for association with phenotypic data for the two estimated puberty ages mentioned above. The association analysis showed a significant association $(\mathrm{P}<0.05)$ between the haplotype markers and puberty age estimated at C50 and M10. Homozygote TGT exhibited a mean +/- S.E. age at C50 and M10 of $289.74 \pm 8.13$ days, while homozygote CAG showed $347.67 \pm 22.51$ days, resulting in a difference of 57.93 days of age. Heterozygote animals showed a mean +/- S.E. age of $299.65 \pm 8.72$ days of age. No significant association was found between both haplotypes and age at puberty estimated at SC28 $(\mathrm{TGT} / \mathrm{TGT}=277.95 \pm 23.85$ days, $\mathrm{TGT} / \mathrm{CAG}=281.09 \pm$ 25.82 days and $\mathrm{CAG} / \mathrm{CAG}=292.00 \pm 17.76$ days, $\mathrm{P}>0.05)$. 
The results obtained here constitute the first report of an association of TG gene polymorphisms with age of puberty in bulls and could be explained by the vast amount of works in which the modulatory influence of THs on male reproduction is demonstrated (Flood et al., [8], Duarte-Guterman et al., [9]). The potential of THs in the modulation of male reproductive functions during or preceding puberty was determined to be of such importance at the point that any alteration in their expression and/ or concentration has profound effects on male reproduction (Krassas et al., [11], Weber et al., [20]). Despite the indirect regulation of sexual maturation by $\mathrm{THs}$ through their known roles in development, metabolism, hormonal regulation and other physiological processes, evidence indicates that THs have direct effects on sexual development, reproductive function and associated molecular mechanisms and pathways. Although the specific mechanisms underlying this regulation are not completely established, these direct effects could be exerted mainly through the presence of $\mathrm{TH}$ machinery in gonadal tissues. For example, TRs are widely distributed and expressed in different compartments of the testis in mammalian species, which suggests a direct regulatory role for THs in male gonadal development and function (Jannini et al., [6], Kumar et al., [21], Wagner et al., [10]). Studies have also identified deiodinases in the testes of vertebrate species, whose role within testicular functioning in mammalian species has been reviewed by Wagner et al., [10]. Another evidence for the involvement of THs in puberty is the presence of TREs in androgen receptors in the testis and in GnRH and luteinizing hormone receptor (LHR) promoter region (Tsai-Morris et al., [22]), which demonstrates that THs can directly regulates androgen biosynthesis. Hyper- and hypo-thyroidic conditions alter $\mathrm{GnRH}$ concentrations in mammals, consequently affecting $\mathrm{LH}$ and FSH production and secretion (Chiao et al., [23]). Furthermore, several studies have shown a fall in circulating testosterone levels in hypothyroid humans (Kumar et al, [21]). As we said before, this regulation is bidirectional and there area lot of studies describing the considerable cross-regulation existing between HPT and HPG axes in vertebrates. Interestingly, Fortes et al., [24] detected SERPINA7 gene on chromosome X associated with percentage of normal sperm (PNS) in Brahman bulls. This gene codes for thyroxine-binding globulin (TBG), the major TH transport protein in serum. This evidence reinforces the hypothesis that THs play an important role in bovine male fertility.

Despite the broad range of effects in vertebrates and the connections in nearly every biological endocrine system, a lot of studies provide enough evidence to confirm the role of THs in sexual differentiation and gonadal development in mammalian and non-mammalian species. We can affirm that THs influence steroidogenesis and spermatogenesis and as described above there is extensive evidence that links TG gene to testicular development, existing a direct crosstalk between HPG and thyroid hormones axis (Wagner et al., [10], Nonneman et al., [25]).

\section{Conclusions}

In conclusion, we detected an association between TG polymorphisms and age at puberty at C50 and M10 in male Angus cattle. Our results could contribute to the investigation on regulation of bovine puberty and fertility. THs are essential for normal growth, sexual development and reproductive function, and normal thyroid activity seems to be a requisite for an adequate male reproductive function. However, the knowledge about the interaction between both endocrine axis, HTP and HTG, is still rudimentary and needs further investigation.

\section{Competing interests}

None of authors of this paper has financial, personal or other relationship with other people or organizations that could inappropriately influence the content of this paper.

\section{Authors' contribution}

MEF and DEG participated in the genetic and statistical studies, drafted the manuscript. AP conceptualized the study and collected the phenotypic data. PPG participated in the design of the study. AB conceptualized the study and collected the phenotypic data. GG and JPL conceptualized and supervised the whole study, analyzed the data, performed the statistical analysis, drafted the manuscript. All authors read and approved the final version of the manuscript.

\section{Author details}

${ }^{1}$ Instituto de Genética Veterinaria (IGEVET), CCT La Plata - CONICET - Facultad de Ciencias Veterinarias, Universidad Nacional de La Plata, Calle 60 y 118 s/n, La Plata B1900AWW, CC 296, Argentina. ²Departamento de Producción Animal, Facultad de Ciencias Veterinarias, Universidad Nacional de La Plata, La Plata, Argentina. ${ }^{3}$ Fellow of the Consejo Nacional de Investigaciones Científicas y Técnicas (CONICET), La Plata, Argentina.

Received: 18 July 2014 Accepted: 12 September 2014

Published: 16 September 2014

\section{References}

1. Ojeda SR, Dubay C, Lomniczi A, Kaidar G, Matagne V, Sandau US, Dissen GA: Gene networks and the neuroendocrine regulation of puberty. Mol Cell Endocrinol 2010, 324:3-11.

2. Johnston DJ, Barwick SA, Corbet NJ, Fordyce G, Holroyd RG, Williams PJ, Burrow HM: Genetics of heifer puberty in two tropical beef genotypes in northern Australia and associations with heifer and steer-production traits. Anim Prod Sci 2009, 49:399-412.

3. Fortes MRS, Lehnert SA, Bolormaa S, Reich C, Fordyce G, Corbet NJ, Whan V, Hawken RJ, Reverter A: Finding genes for economically important traits: Brahman cattle puberty. Anim Prod Sci 2012, 52:143-150.

4. Warner A, Mittag J: Thyroid hormone and the central control of homeostasis. J Mol Endocrinol 2012, 49:29-35.

5. Mullur R, Liu YY, Brent GA: Thyroid hormone regulation of metabolism. Physiol Rev 2014, 94(Suppl2):355-382.

6. Jannini EA, Crescenzi A, Rucci N, Screponi E, Carosa E, de Matteis A, Macchia E, d'Amati G, D'Armiento M: Ontogenetic pattern of thyroid hormone receptor expression in the human testis. J Clin Endocrinol Metab 2000, 85:3453-3457.

7. Mendis-Handagama SM, Siril Ariyaratne HB: Leydig cells, thyroid hormones and steroidogenesis. Indian J Exp Biol 2005, 43(Suppl11):939-962.

8. Flood DE, Fernandino Jl, Langlois VS: Thyroid hormones in male reproductive development: evidence for direct crosstalk between the androgen and thyroid hormone axes. Gen Comp Endocrinol 2013, 192:2-14. 
9. Duarte-Guterman P, Navarro-Martín L, Trudeau VL: Mechanisms of crosstalk between endocrine systems: Regulation of sex steroid hormone synthesis and action by thyroid hormones. Gen Comp Endocrinol 2014, doi:10.1016/j. ygcen.2014.03.015.

10. Wagner MS, Wajner SM, Maia AL: Is there a role for thyroid hormone on spermatogenesis? Microsc Res Tech 2009, 72:796-808.

11. Krassas GE, Papadopoulou F, Tziomalos K, Zeginiadou T, Pontikides N: Hypothyroidism has an adverse effect on human spermatogenesis: A prospective, controlled study. Thyroid 2008, 18(Suppl12):1255-1259.

12. Ram PA, Waxman DJ: Pretranslational control by thyroid hormone of rat liver steroid 5 alpha-reductase and comparison to the thyroid dependence of two growth hormone-regulated CYP2C mRNAs.J Biol Chem 1990, 265(31):19223-19229.

13. Zhou RJ, Bonneaud N, Yua CX, Barbara PD, Boizet B, Tibor S, Scherer G, Roeder RG, Poulat F, Berta P: SOX9 interacts with a component of the human thyroid hormone receptor-associated protein complex. Nucleic Acids Res 2002, 30(Suppl 14):3245-3252.

14. Zhao L, Bakke M, Krimkevich Y, Cushman LJ, Parlow AF, Camper SA, Parker $\mathrm{KL}$ : Steroidogenic factor 1 (SF1) is essential for pituitary gonadotrope function. Development 2001, 128(Suppl 2):147-154.

15. Sugawara T, Kiriakidou M, McAllister JM, Holt JA, Arakane F, Strauss JF: Regulation of expression of the steroidogenic acute regulatory protein (StAR) gene: a central role for steroidogenic factor 1. Steroids 1997, 62:5-9.

16. Pelletier G: Localization of androgen and estrogen receptors in rat and primate tissues. Histol Histopathol 2000, 15:1261-1270.

17. Hou GY, Yuan ZR, Zhou HL, Zhang LP, Li JY, Gao X, Wang DJ, Gao HJ, Xu SZ: Association of thyroglobulin gene variants with carcass and meat quality traits in beef cattle. Mol Biol Rep 2011, 38:4705-4708.

18. Lirón JP, Prando A, Fernández ME, Ripoli MV, Rogberg-Muñoz A, Goszczynski DE, Posik DM, Peral-García P, Baldo A, Giovambattista G: Association between GNRHR, LHR and IGF1 polymorphisms and timing of puberty in male Angus cattle. BMC Genet 2012, 5:13-26.

19. Li N, Stephens M: Modelling linkage disequilibrium, and identifying recombination hotspots using SNP data. Genetics 2003, 165:221-233.

20. Weber G, Vigone MC, Stroppa L, Chiumello G: Thyroid function and puberty. J Pediatr Endocrinol Metab 2003, 16(Suppl 2):253-257.

21. Kumar A, Shekhar S, Dhole B: Thyroid and male reproduction. Indian J Endocr Metab 2014, 18(Suppl 1):23-31.

22. Tsai-Morris $\mathrm{CH}$, Xie XZ, Buczko E, Dufau ML: Promoter and regulatory regions of the rat luteinizing hormone receptor gene. J Biol Chem 1993, 268(Suppl 6):4447-4452.

23. Chiao YC, Lee HY, Wang SW, Hwang JJ, Chien CH, Huang SW, Lu CC, Chen $\mathrm{JJ}$, Tsai SC, Wang PS: Regulation of thyroid hormones on the production of testosterone in rats. J Cell Biochem 1999, 73:554-562.

24. Fortes MRS, Reverter A, Hawken RJ, Bolormaa S, Lehnert SA: Candidate Genes Associated with Hormone Levels of Inhibin, Luteinising Hormone, and Insulin-Like Growth Factor 1, Testicular Development, and Sperm Quality in Brahman Bulls. Biol Reprod 2012, 87(Suppl 3):58.

25. Nonneman D, Rohrer GA, Wise TH, Lunstra DD, Ford JJ: A variant of porcine thyroxine-binding globulin has reduced affinity for thyroxine and is associated with testis size. Biol Reprod 2005, 72:214-220.

doi:10.1186/2055-0391-56-17

Cite this article as: Fernández et al:: Assessing the association of single nucleotide polymorphisms in thyroglobulin gene with age of puberty in bulls. Journal of Animal Science and Technology 2014 56:17.

\section{Submit your next manuscript to BioMed Central and take full advantage of:}

- Convenient online submission

- Thorough peer review

- No space constraints or color figure charges

- Immediate publication on acceptance

- Inclusion in PubMed, CAS, Scopus and Google Scholar

- Research which is freely available for redistribution 